\title{
Effect of Microstructure on the Thermal Properties of Sintered Iron-copper Composites
}

\author{
Caroline Velasques Ugarteche ${ }^{a *}$, Kaline Pagnan Furlan ${ }^{a}$, Rafaela do Vale Pereira ${ }^{a}$, \\ Gabriel Trindade ${ }^{a}$, Roberto Binder ${ }^{b, c}$, Cristiano Binder ${ }^{a}$, Aloisio Nelmo Klein ${ }^{a}$ \\ ${ }^{a}$ Materials Laboratory - LabMat, Mechanical Engineering Department, Universidade Federal de Santa \\ Catarina - UFSC, Campus Reitor João David Ferreira Lima, Bairro Trindade, \\ CEP 88040-900, Florianópolis, SC, Brazil \\ ${ }^{b}$ Whirlpool, Rua Rui Barbosa, 1020, Distrito Industrial, CEP 89219-521, Joinville, SC, Brazil \\ ${ }^{c}$ Embraco Unit, Rua Rui Barbosa, 1020, Distrito Industrial, CEP 89219-521, Joinville, SC, Brazil
}

Received: May 28, 2015; Revised: October 1, 2015

\begin{abstract}
Copper is a well know material for use as heat sink or heat exchanger. However, copper has a considerable low tensile strength and temperature limit. A material that has a good thermal conductivity, low cost, but also resistance is the desired. Effects of copper on the sintering and thermal properties of iron-copper composites produced by powder metallurgy and $\mathrm{Fe}$ on copper-iron composites have been investigated. Copper and iron were varied from 20 to 80 vol.\% in the samples, alternating the continuous phase. Sintering studies were performed by in-situ dilatometry aiming to define the proper conditions for sintering, without swelling normally associated with copper. Results indicate that the type of sintering, final microstructure, specially the phases relation and distribution and not only the amount of copper, have a great effect into the thermal properties. By controlling the sintering parameters, it is possible to obtain dimensionally stable samples with higher thermal conductivity and lower copper amount.
\end{abstract}

Keywords: thermal properties, copper-iron, sintered composites, microstructure

\section{Introduction}

The crescent demand for high efficiency systems has attracted the attention of researchers to the thermal property of materials. The most studied materials for thermal application are usually composed by an aluminium or copper matrix - due to their high thermal conductivity - or iron - due to the large usage of iron and its alloys as raw material for mechanical system parts ${ }^{1-5}$. Silicon carbide and diamond are widely used as additives, having high thermal conductivity and low thermal expansion that improve the dimensional stability of these composites ${ }^{6-10}$.

Parts that overheat during its operation in mechanical systems intensify the energy losses in these systems. The heat is a type of energy and to understand how this energy flows along the systems may help to control and optimize the thermal management of components. Furthermore, for this management to be more accurate it is also important to study the thermal properties of the materials used to produce the parts in these systems.

Thermal conductivity $(\mathrm{K})$ can be expressed as the product of thermal diffusion $(\propto)$, density $(\rho)$, and specific heat $(\mathrm{Cp})$ of the material, as showed on Equation $1^{11}$.

$K=\propto * \rho * C p$

The conductivity of a material produced by powder metallurgy (PM) is strongly affected by the material porosity, which is an inherent characteristic of PM parts.

*e-mail: caroline.ugarteche@posgrad.ufsc.br
Besides porosity, the interface between different phases in the microstructure, as well as powder initial shape and surface chemical characteristics can also affect the thermal conductivity $^{3}$. In heterogeneous materials, the thermal conductivity is also affected by the phases distribution and chemical composition, especially when there is the formation of solid solutions or intermetallics, which can decrease the thermal conductivity of the component ${ }^{12}$. There are many studies aiming to predict or simulate the thermal conductivity of materials accordingly to their initial components and microstructure. However, until now no model can be applied and satisfy all types of materials ${ }^{12}$.

Wang et al. ${ }^{12}$ proposed a model to explain how the heat flows through a dual phase material comprised by dispersed spheres on a homogeneous matrix, where the dispersed material has a different thermal conductivity than the matrix. It is proposed that the heat flows mainly along the more conductive phase. Therefore, for a material comprising iron and copper, for example, it is expected that the heat would flow by the copper phase. For this reason, it is important to study the amount of copper that would be necessary to assure a high conductivity to an iron matrix, in order to improve the thermal properties of the whole component.

The aim of this study is to investigate the effects of copper additions on the sintering behaviour, microstructure and thermal properties of iron-copper composites produced by powder metallurgy and also iron on copper-iron composites. Moreover it has as an objective, by monitoring sintering 
inside a dilatometer and performing different cycles in a resistive furnace, to define the most appropriate sintering cycle concerning dimensional stability and microstructural control of the samples. After defining the most suitable cycle for each type of composite, the samples microstructures were characterized by density measurements, optical and electronic microscopy and these results were associated with the thermal conductivity measurements realized by laser flash technique.

\section{Experimental Procedure}

During this work samples were produced by powder metallurgy route with two different matrixes: iron and copper. The powders used as raw material were Fe (Högänas $-\mathrm{d}_{50}=100 \mathrm{um}$ ) and $\mathrm{Cu}$ (Epson Atmix $-\mathrm{d}_{50}=10 \mathrm{um}$ ). The powders were mixed in the proportions described in Table 1 in a Y-shape mixer during one hour. The Group \#1 is composed by samples of iron and copper, where iron is the matrix and copper the second phase. Group \#2 is formed by copper and iron samples, where copper is the matrix and iron the second phase. The samples (cylindrical billets of 6 and $20 \mathrm{~mm}$ diameter) were uniaxially cold pressed at $700 \mathrm{MPa}$ (Skay code 1663 and Gabrielli semi-automatic).

At first, the sintering behaviour of the samples was investigated by dilatometry (Netzsch $402 \mathrm{C}$ ) and differential thermal analysis (DTA/TG - Netzsch STA 449 F3). The atmosphere used on both cases was a mixture of Argon $+5 \%$ Hydrogen. Afterwards the sintering was performed in a tubular resistive furnace (Fortelab, AISI 316 stainless steel tube as sintering retort) at the same atmosphere. The cycles of Group \#1 had liquid-phase sintering and Group \#2 solid state sintering. In Group \#1 the samples were heated until $1080{ }^{\circ} \mathrm{C}$ at $10^{\circ} \mathrm{C} / \mathrm{min}$ and stayed at this temperature for
10 minutes, in order to equalize the temperature along the samples. After that, the temperature was raised to $1090{ }^{\circ} \mathrm{C}$ at $5^{\circ} \mathrm{C} / \mathrm{min}$, where a dwell time of 5 minutes took place. This temperature is higher than the copper melting point, and a copper liquid phase is formed and spread in the samples, however only little swelling occur. The last step is to lower the temperature to $1050{ }^{\circ} \mathrm{C}$ for a dwell time of 60 minutes. Samples of Group \#2 were heated at $10^{\circ} \mathrm{C} / \mathrm{min}$ until $900^{\circ} \mathrm{C}$ where a dwell time of 60 minutes occurred.

The measurement of thermal diffusivity was carried out in a LFA447 Netzsch equipment using the laser-flash technique. The samples were covered with a graphite thin film to guarantee that all the energy is absorbed. The samples were 3-5 mm thick. The thermal conductivity was calculated using the thermal diffusivity values, according to the method described in ${ }^{13,14}$. The samples densities were measured and the specific heat calculated by the rule of mixtures (Equation 2), where $\mathrm{Cp}$ is the specific heat and $\mathrm{f}$ the proportion of each phase.

$C p \operatorname{mix}=C p 1 * f 1+C p 2 * f 2+C p 3 * f 3$

Each sample was considered being composed by iron, copper and pores - phases 1,2 and 3. The porosity was estimated based on the comparison between the theoretical and the measured density.

\section{Results and Discussion}

The microstructural analysis shows that both sintering temperature and time had influence in the formation of a continuous copper phase. Only raising the temperature to $1090{ }^{\circ} \mathrm{C}$ with a dwell time of 15 minutes (liquid phase sintering), was not enough to form this continuous phase (see Figure 1). To raise the temperature up to $1125^{\circ} \mathrm{C}$ (liquid phase sintering as well) had an even worse effect with copper
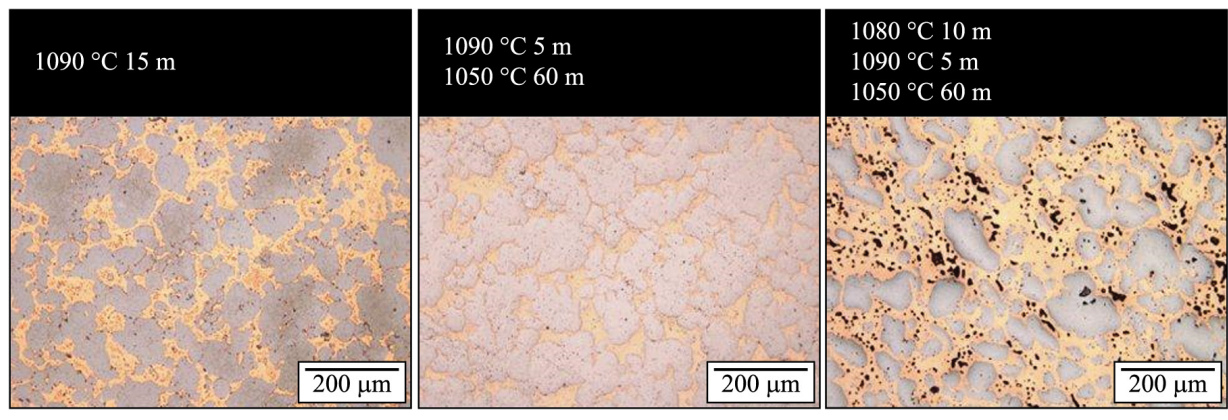

Figure 1. Microstructures of iron matrix composites with 40 vol. \% of copper sintered at different conditions. Optical microscopy, 200×.

Table 1. Composition of the samples.

\begin{tabular}{cccccc}
\hline & Sample & Matrix & Additive & Additive (vol. \%) & Cu (vol. \%) \\
\hline \multirow{5}{*}{ Group\#1 } & $\mathrm{Fe}$ & $\mathrm{Fe}$ & none & 0 & 0 \\
& $\mathrm{FeCu} 20$ & & & 20 & 20 \\
& $\mathrm{FeCu} 30$ & $\mathrm{Fe}$ & $\mathrm{Cu}$ & 30 & 30 \\
& $\mathrm{FeCu} 40$ & & & 40 & 40 \\
\hline \multirow{5}{*}{ Group\#2 } & $\mathrm{Cu}$ & $\mathrm{Cu}$ & $\mathrm{Fe}$ & 20 & 80 \\
& $\mathrm{CuFe} 20$ & $\mathrm{Cu}$ & & 30 & 70 \\
& $\mathrm{CuFe} 30$ & & & 40 & 60 \\
\hline
\end{tabular}


sublimation occurring for sintering cycles performed at atmosphere pressure (Figure 2). Those samples were also deformed, presenting expansion (swelling) in the height and also poor surface quality.

A small variation in the sintering conditions had a massive effect on the microstructural aspect. For iron matrix composites, the best condition was achieved by a combination of liquid phase and solid state sintering. While for the cycle without a previous dwell time $\left(1090{ }^{\circ} \mathrm{C}-5 \mathrm{~min}+1050{ }^{\circ} \mathrm{C}\right.$ $60 \mathrm{~min}$ ) there is no copper continuous phase, a small dwell time before the liquid phase formation (10 minutes at $1080^{\circ} \mathrm{C}$ ) for temperature homogenization led to the desired microstructure, with the formation of a continuous phase.

For the same sintering cycle, the amount of copper also plays an important role (Figure 3 ). While 40 vol. \% of

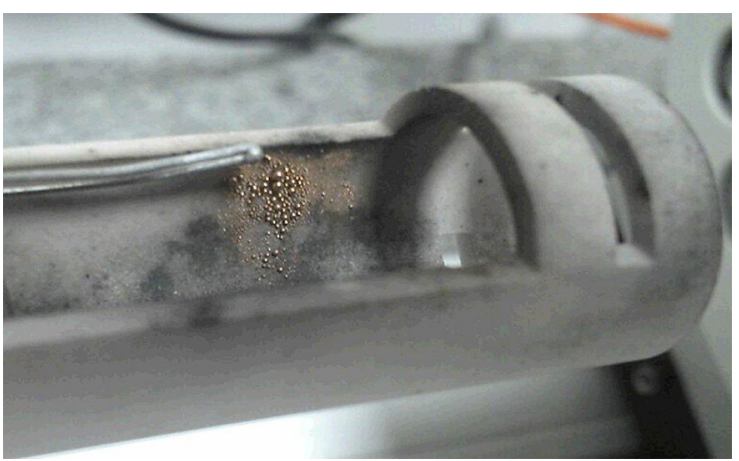

Figure 2. Vaporization of copper inside the dilatometer tube. copper guaranteed a continuous phase, the smaller additions (30 and 20 vol. \%) did not lead to a formation of a copper continuous phase.

For the sample with the same amount of additive (20 vol. \%) but different matrix (CuFe20) small and well distributed pores appear along the copper matrix, which could indicate secondary porosity formation due to swelling (Figure 4). In all the copper matrix composites there is a continuous phase of copper and no continuous phase of iron was formed.

All the samples presented oxides in their microstructure. Figure 5a shows the SEM images of a FeCu40 sample. The iron phase is darker on the image, surrounded by the copper phase. Around the iron grains it is possible to identify porous and some oxides. It is assumed that the residual oxygen level on the powder is responsible for these oxides. Because of the high pressure used during pressing $(700 \mathrm{MPa})$, it is possible that the reducing gas $\left(\mathrm{H}_{2}\right)$ was not able to percolate all the sample and reduce these oxides in the middle of the samples within these sintering conditions. The same type of oxides formation can be seen on copper matrix samples, as in the $\mathrm{CuFe} 40$ sample (Figure $5 \mathrm{~b}$ ). The presence of these oxides may reduce the thermal conductivity because they represent an obstacle for the heating flux. Defects along the atoms net can be responsible for lowering the heating conductivity levels ${ }^{15}$.

After choosing the most suitable sintering cycle, considering dimensional stability, surface quality and microstructural aspects, the cycle $\left(1080{ }^{\circ} \mathrm{C}-1090^{\circ} \mathrm{C}-1050^{\circ} \mathrm{C}\right)$ was defined for the iron matrix samples and the cycle $\left(900^{\circ} \mathrm{C}\right)$ for the

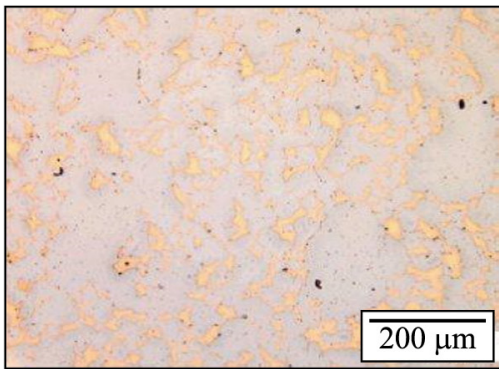

$\mathrm{FeCu} 20$

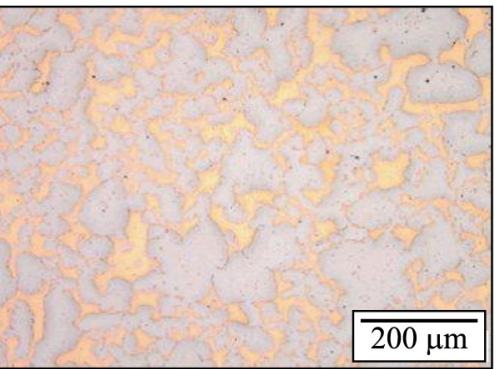

$\mathrm{FeCu} 30$

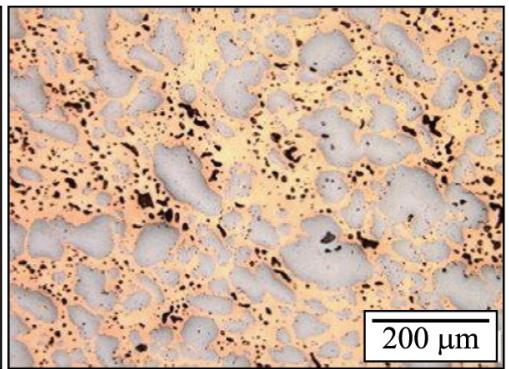

$\mathrm{FeCu} 40$

Figure 3. Microstructures of iron matrix composites with varied amounts $\left(20,30\right.$ and 40 vol. \%) of copper sintered at $1080{ }^{\circ} \mathrm{C}-10 \mathrm{~min}$; $1090^{\circ} \mathrm{C}-5 \mathrm{~min} ; 1050^{\circ} \mathrm{C}-60 \mathrm{~min}$. Optical microscopy, $200 \times$.

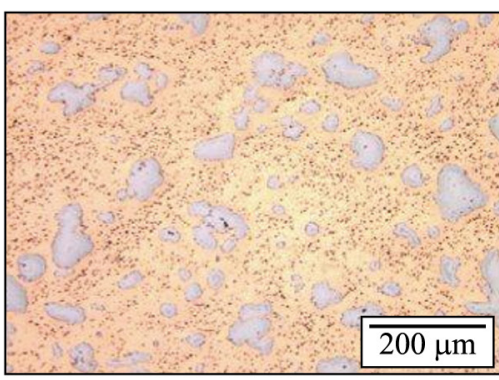

$\mathrm{CuFe} 20$

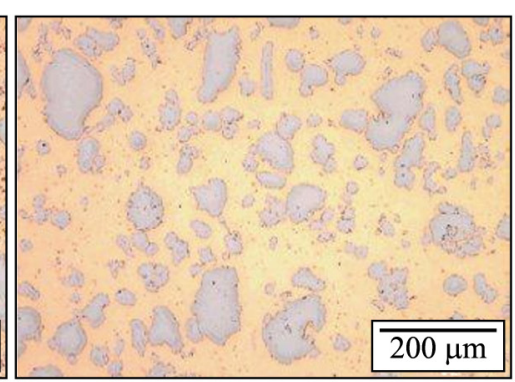

$\mathrm{CuFe} 30$

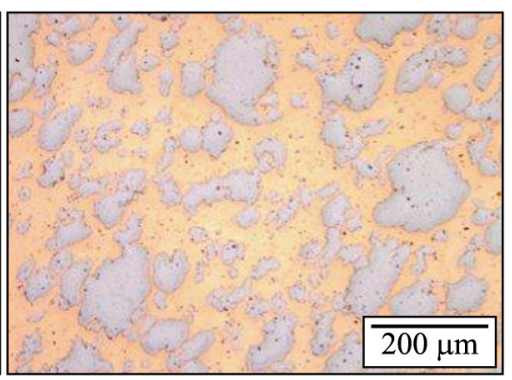

$\mathrm{CuFe} 40$

Figure 4. Microstructures of copper matrix composites with varied amounts (20, 30 and 40 vol. \%) of iron sintered at $900{ }^{\circ} \mathrm{C}-60$ min. Optical microscopy, 200× 
copper matrix samples. Both type of samples had the longest dwell time (60 minutes) of the sintering cycle occurring in the solid state. For the iron matrix samples the short dwell time of 5 minutes in $1090{ }^{\circ} \mathrm{C}$ was enough for copper to became liquid and spread among iron particles, forming a continuous phase (Figure 1), however without massive swelling. It is expected that the heat can flow through this continuous phase.

The sintering investigations performed in the dilatometer for these two types of cycles, with samples containing different additive amounts is shown in Figure 6. It is possible to visualize that the copper matrix samples had a greater linear shrinkage than the iron matrix samples for all the cycles studied (see pure iron sample - dashed line - for comparison). All the iron matrix samples presented a clear swelling, starting around $1020{ }^{\circ} \mathrm{C}$ and becoming more pronounced after $1083^{\circ} \mathrm{C}$ (see sample $\mathrm{FeCu} 40$ ). This swelling was reduced though, by lowering the temperature right after liquid phase dwell time $\left(1090{ }^{\circ} \mathrm{C}\right.$ for $\left.5 \mathrm{~min}\right)$ and sintering these samples in solid state at $1050{ }^{\circ} \mathrm{C}$ during 60 minutes.

For these kind of samples, iron matrix, the higher the copper amount, the higher was the final linear shrinkage (FeCu40). Conversely, for the copper matrix samples, there is no clear trend. It was expected that the samples with higher copper amount $(\mathrm{CuFe} 20)$ would present the higher shrinkage, which was confirmed, however the sample with 30 vol.\% $\mathrm{Fe}(\mathrm{CuFe} 30)$ presented a lower shrinkage than the one with a higher amount of iron (40 vol. \%, CuFe40).

Moreover, all the iron matrix samples presented the transformation of ferrite (iron, bcc) to austenite (iron, FCC) during heating at approximately $920{ }^{\circ} \mathrm{C}$ (better visualized in Figure 7). During cooling, samples also showed this transformation, however at a lower temperature $\left(800^{\circ} \mathrm{C}\right)$, when comparison with pure iron $\left(900^{\circ} \mathrm{C}\right)$. Thus indicating the diffusion of copper into iron which stabilizes austenite, lowering the transformation temperature, or in other words

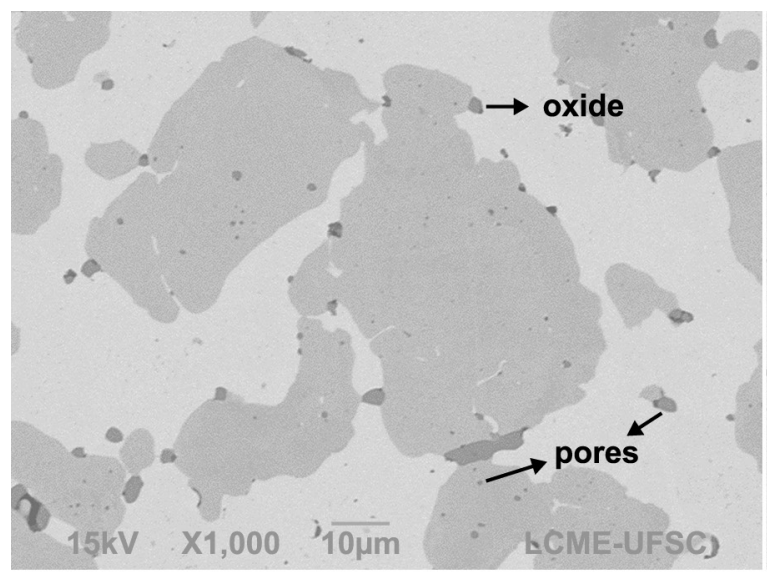

(a)

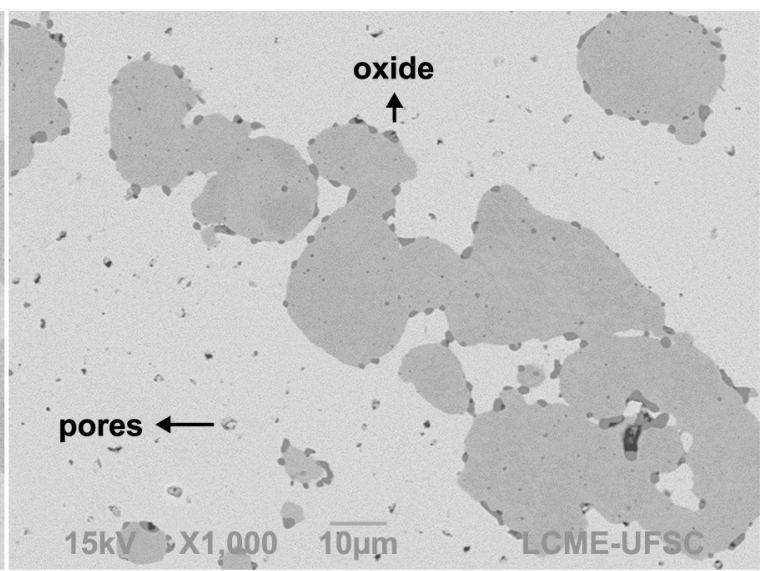

(b)

Figure 5. SEM image of sintered samples (a) FeCu $401080{ }^{\circ} \mathrm{C}-1090{ }^{\circ} \mathrm{C}-1050{ }^{\circ} \mathrm{C}$; (b) $\mathrm{CuFe} 40900{ }^{\circ} \mathrm{C}$.

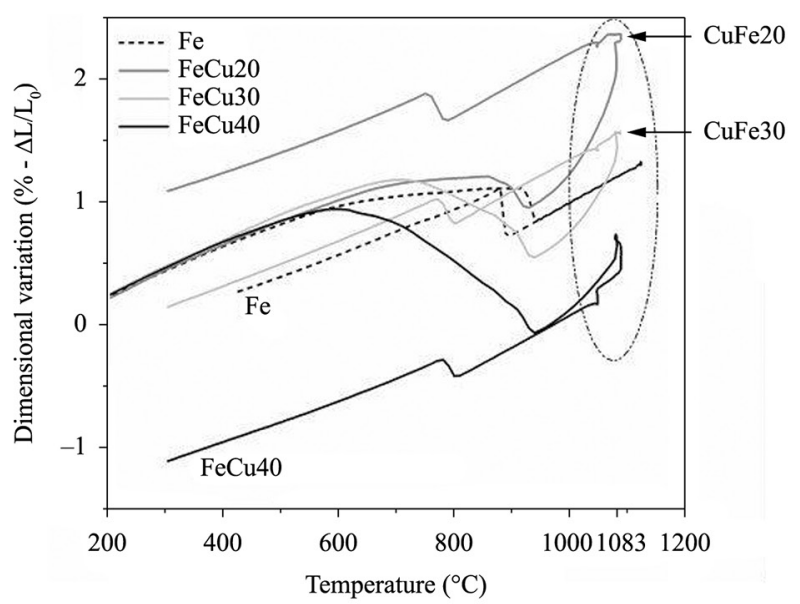

(a)

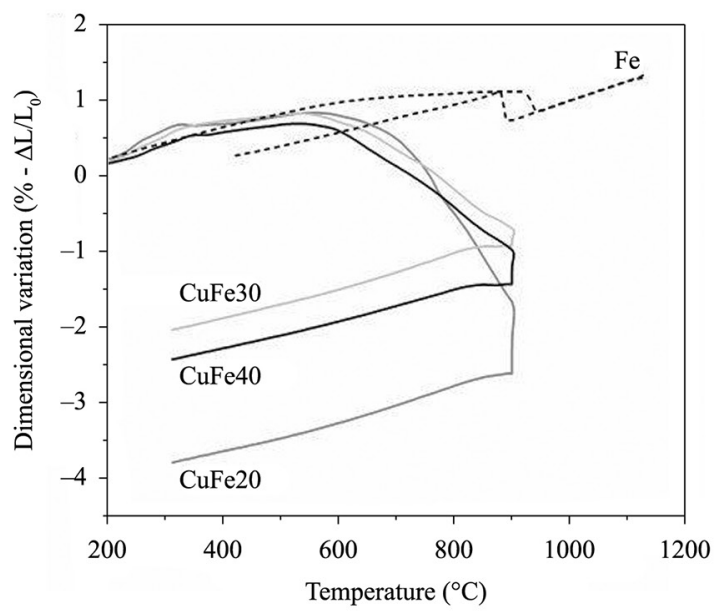

(b)

Figure 6. Dimensional behaviour of (a) iron matrix samples; and (b) copper matrix samples during its sintering in a dilatometer (note the different scale for dimensional variation). 
expanding the $\gamma$-field. This transformation temperature during cooling is influenced by the amount of copper diffused into iron, which has a maximum value that is not dependent on the amount of initial copper added to the mixture, i.e. the

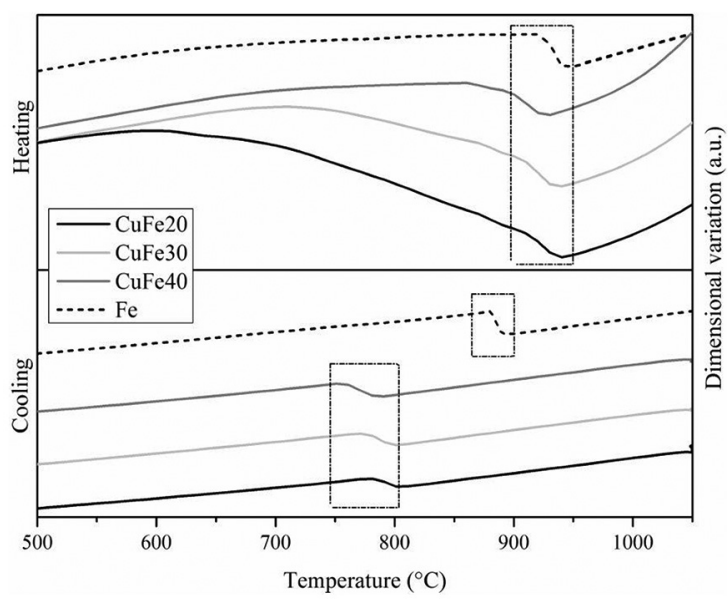

Figure 7. Allotropic transformations (square markers) for the iron matrix samples.

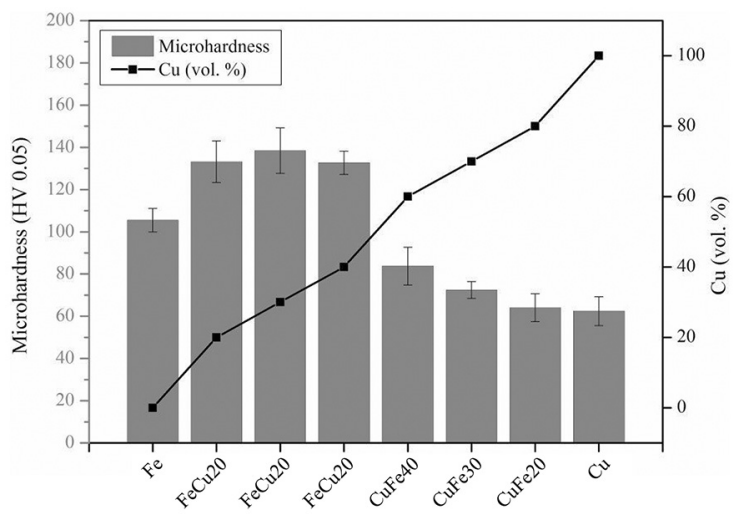

Figure 8. Sintered samples microhardness according to the initial copper content.

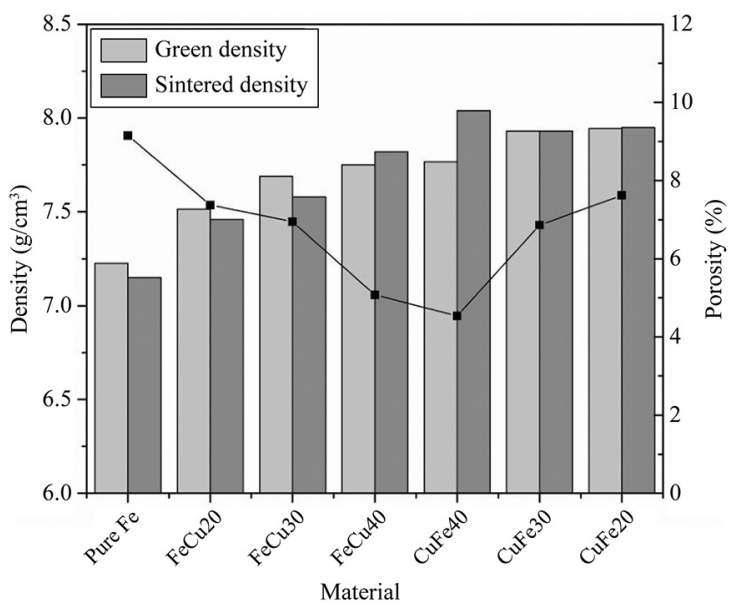

Figure 9. Green and sintered (geometrical density) of the samples and evolution of the porosity. minimum amount added $(20 \% \mathrm{wt})$ is already higher than the maximum solubility ${ }^{16}$.

The samples microhardness (Figure 8) shows that this diffusion caused a solid solution strengthening effect in both type of samples (iron or copper matrix).

Figure 9 shows the measured density and porosity for the sintered samples. Following the trend of the sintering studies, for the iron matrix samples, as higher the copper level in the sample, higher is the sintered density, even though the results were quite similar. For the copper matrix samples it was not possible to make a correlation with the linear shrinkage results. The samples with 40 vol. \% of copper $(\mathrm{FeCu} 40)$ and iron $(\mathrm{CuFe} 40)$ were the ones with higher densities in each group.

Either way the porosity on samples is directly influenced by the copper amount (Figure 10) and has different behaviour inside each group of composites. For the iron matrix composites, the higher the copper amount, lower is the porosity. On the other hand, for the copper matrix composites, the higher the copper amount, the higher is the porosity, which indicates swelling during sintering and/or secondary porosity formation.

The high value of porosity found in Group \#1 (remembering that this group is sintered at $1090-1080-1050{ }^{\circ} \mathrm{C}$ while the group \#2 is sintered at $900{ }^{\circ} \mathrm{C}$ ) can be explained by a combination of factors: The lower wettability of liquid copper to solid iron, does not allow the properly densification of the samples ${ }^{17,18}$; The difference between diffusion coefficients, where the diffusion rates of copper into iron is higher than the opposite, generating residual voids into the copper phase ${ }^{19}$ and the temperature of $1050^{\circ} \mathrm{C}$, which is considered as a low temperature for sintering iron samples. It is believed that the sample FeCu40, produced by a combination of liquid-phase and solid state sintering, presented less porosity due to the high copper content that on this case allowed good sintering characteristics.

This porosity influenced the thermal conductivity of samples (Figure 11). It is possible to visualize that when the porosity levels are higher the thermal conductivity tends to be lower. For example, $\mathrm{FeCu} 40$ and $\mathrm{CuFe} 40$ both with lower

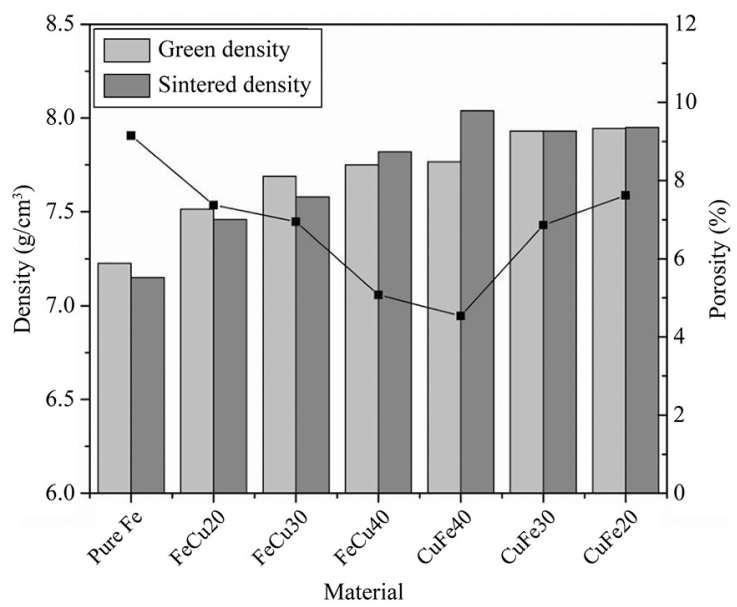

Figure 10. Influence of initial amount of copper on the porosity of sintered samples. 


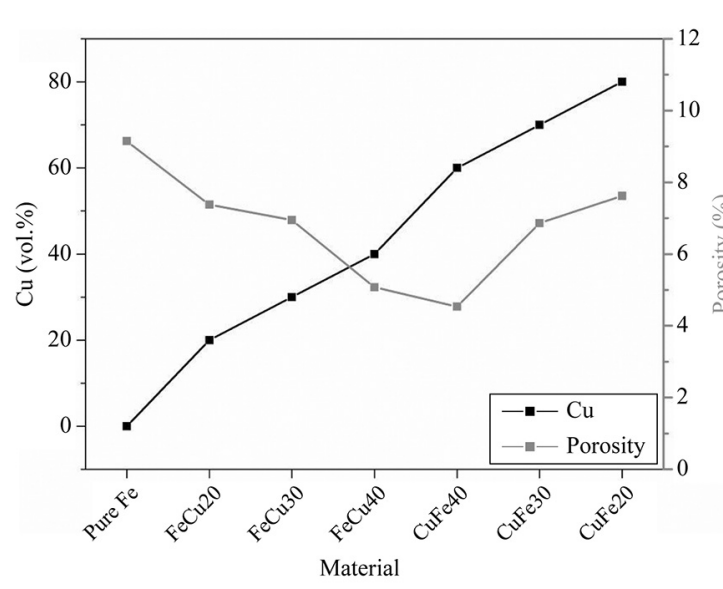

Figure 11. Influence of sintered samples porosity on the thermal conductivity.

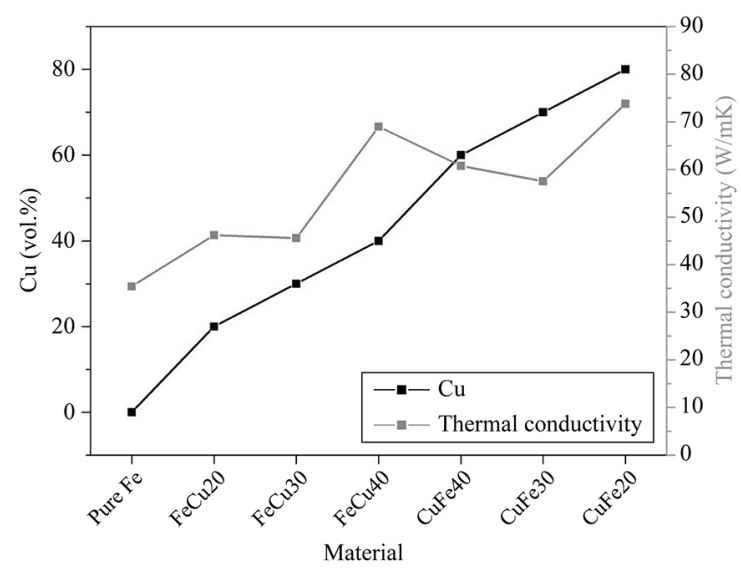

Figure 12. Influence of copper initial content on the thermal conductivity of sintered samples.

porosity level, presented higher thermal conductivity values. Except for the sample $\mathrm{CuFe} 20$, due to its high copper level (80\%), even a high porosity $(\sim 7.5 \%)$ did not lead to lower values on thermal conductivity. Furthermore, not only the

\section{References}

1. Davis JR. Copper and copper alloys. Ohio: ASM International; 2001.

2. Liu Q, He X-B, Ren S-B, Liu T-T, Kang Q-P and Qu X-H. Fabrication and thermal conductivity of copper matrix composites reinforced with Mo2C or TiC coated graphite fibers. Materials Research Bulletin. 2013; 48(11):4811-4817. http://dx.doi. org/10.1016/j.materresbull.2013.07.064.

3. Vincent C, Silvain JF, Heintz JM and Chandra N. Effect of porosity on the thermal conductivity of copper processed by powder metallurgy. Journal of Physics and Chemistry of Solids. 2012; 73(3):499-504. http://dx.doi.org/10.1016/j. jpcs.2011.11.033.

4. Zhang Z, Sandström R and Wang L. Modelling of swelling of $\mathrm{Fe}-\mathrm{Cu}$ compacts sintered at temperatures above the copper melting point. Journal of Materials Processing amount, but also the shape and distribution of voids may also influence on the thermal conductivity.

Figure 12 shows the thermal conductivity evolution with the amount of copper in the samples. At the same time when the copper levels increase also does the thermal conductivity. Sample $\mathrm{FeCu} 40$ that has $40 \%$ of copper on its composition and lowest pores level $(4.53 \%)$ among the samples inside group \#1, reached as good thermal conductivity levels as the sample with $80 \%$ of copper $(\mathrm{CuFe} 20)$, which has a slightly higher porosity $(5.07 \%)$. Both factors, low pores content and $\mathrm{Cu}$ amount contribute to increase thermal conductivity.

\section{Conclusions}

The Group \#1 sintering conditions were effective for producing liquid phase without dimensional instability or swelling. A copper continuous phase was observed when the amount of copper was $40 \%$ on Group \#1 and in all the samples from Group \#2.

For the composites, the porosity level negatively influenced the thermal conductivity. On the ferrous matrix group, the higher is the copper level, the lower is the porosity and there is an increase in the thermal conductivity. On the other group (copper matrix), there is no clear trend between copper amount, porosity and thermal conductivity. It is possible that the shape and distribution of voids and oxides had a greater influence in these type of samples.

Nevertheless, composites of both groups had a better conductivity performance than the pure iron sample. For the iron matrix composites, the best thermal conductivity was observed for $40 \%$ of copper addition ( $\mathrm{FeCu} 40)$, which was almost $100 \%$ more conductor than pure iron sample and it had similar thermal conductivity of the sample containing $80 \%$ of copper $(\mathrm{CuFe} 20)$. The association of an adequate microstructure with a copper continuous phase plus low porosity, obtained by controlling sintering (with liquid phase formation but avoiding swelling) led to this result.

\section{Acknowledgements}

To CAPES, Whirlpool/Embraco and BNDES for the research funding. To LADEQ and LTTC/COPPE UFRJ for Nanoflash equipment. Research supported by LCME-UFSC.

Technology. 2004; 152(2):131-135. http://dx.doi.org/10.1016/j. jmatprotec.2004.03.025.

5. Kong J, Zhang $\mathrm{C}$ and Cheng $\mathrm{X}$. Novel $\mathrm{Cu}-\mathrm{Cr}$ alloy matrix CNT composites with enhanced thermal conductivity. Applied Physics. A, Materials Science \& Processing. 2013; 112(3):631636. http://dx.doi.org/10.1007/s00339-013-7839-4.

6. Chee CYA and Azmi A. Preparation and Characterization of Copper/Copper Coated Silicon Carbide Composites. International Journal of Precision Engineering and Manufacturing. 2014; 15(6):1215-1221. http://dx.doi. org/10.1007/s12541-014-0459-x.

7. Chen $\mathrm{H}$, Jia $\mathrm{C}$ and Li S. Interfacial characterization and thermal conductivity of diamond/Cu composites prepared by two HPHT techniques. Journal of Materials Science. 2011; 47(7):33673375. http://dx.doi.org/10.1007/s10853-011-6180-6. 
8. $\mathrm{Hu} \mathrm{H}$ and Kong J. Improved thermal performance of diamondcopper composites with boron carbide coating. Journal of Materials Engineering and Performance. 2013; 23(2):651-657. http://dx.doi.org/10.1007/s11665-013-0780-z.

9. Mańkowski P, Dominiak A, Domański R, Kruszewski MJ and Ciupiński $Ł$. Thermal conductivity enhancement of copperdiamond composites by sintering with chromium additive. Journal of Thermal Analysis and Calorimetry. 2014; 116(2):881-885. http://dx.doi.org/10.1007/s10973-013-3604-3.

10. Zweben C. Advances in composite materials for thermal management in. JOM. 1998; 50(6):47-51. http://dx.doi. org/10.1007/s11837-998-0128-6.

11. Resnick R, Halliday D and Kenneth SK. Fundamentos de fisica. 8th ed. Rio de Janeiro: Livros Tecnicos e Cientificos; 2009. v. 2.

12. Wang J, Carson JK, North MF and Cleland DJ. A new approach to modelling the effective thermal conductivity of heterogeneous materials. International Journal of Heat and Mass Transfer. 2006; 49(17-18):3075-3083. http://dx.doi.org/10.1016/j. ijheatmasstransfer.2006.02.007.

13. Gaal PS, Thermitus M and Stroe DE. Thermal conductivity measurements using the flash method. Journal of Thermal
Analysis and Calorimetry. 2004; 78(1):185-189. http://dx.doi. org/10.1023/B:JTAN.0000042166.64587.33.

14. Parker WJ, Jenkins RJ, Butler CP and Abbott GL. Flash method of determining thermal diffusivity, heat capacity, and thermal conductivity. Journal of Applied Physics. 1961; 32(9):16791684. http://dx.doi.org/10.1063/1.1728417.

15. Yang J. Theory of thermal conductivity. In: Tritt TM, editor. Thermal conductivity theory, properties, and applications. Heidelberg: Springer; 2004.

16. American Society for Metals - ASM. Alloy phase diagram. Ohio: ASM International; 1992. ASM Handbook, v. 3.

17. German RM, Suri P and Park SJ. Review: liquid phase sintering. Journal of Materials Science. 2008; 44(1):1-39. http://dx.doi. org/10.1007/s10853-008-3008-0.

18. Villanueva W, Grönhagen K, Amberg G and Ågren J. Multicomponent and multiphase simulation of liquid-phase sintering. Computational Materials Science. 2009; 47(2):512520. http://dx.doi.org/10.1016/j.commatsci.2009.09.018.

19. Callister WD and Rethwisch DG. Ciência e engenharia de materiais: uma introdução. 8th ed. Rio de Janeiro: Livros Técnicos e Científicos; 2012. 